\title{
Using GOCI Retrieval Data to Initialize and Validate a Sediment Transport Model for Monitoring Diurnal Variation of SSC in Hangzhou Bay, China
}

\author{
Xuefei Yang ${ }^{1,2}$, Zhihua Mao ${ }^{1,2}{ }^{*}$, Haiqing Huang ${ }^{1}$ and Qiankun Zhu ${ }^{1}$ \\ 1 State Key Laboratory of Satellite Ocean Environment Dynamics, Second Institute of Oceanography, \\ State Oceanic Administration, Hangzhou 310012, China; yxuefei@sina.cn (X.Y.); \\ huanghaiqing@sio.org.cn (H.H.); zhuqiankun@sio.org.cn (Q.Z.) \\ 2 Shanghai Institute of Technical Physics, Chinese Academy of Sciences, Shanghai 200083, China \\ * Correspondence: mao@sio.org.cn; Tel./Fax: +86-571-8196-3115
}

Academic Editor: Jochen Aberle

Received: 31 December 2015; Accepted: 16 March 2016; Published: 19 March 2016

\begin{abstract}
The diurnal variation of the suspended sediment concentration (SSC) in Hangzhou Bay, China has been investigated using remotely-sensed SSC derived from the Geostationary Ocean Color Imager (GOCI) in combination with a coupled hydrodynamic-ecological model for regional and shelf seas (COHERENS). The SSC maps were inferred through a UV-AC atmospheric correction algorithm and an empirical inversion algorithm from the GOCI Level-1B data. The sediment transport model was initialized from maps of the GOCI-derived SSC and the model results were validated through a comparison with remotely-sensed data. The comparison demonstrated that the model results agreed well with the observations. The relationship between SSC distribution and hydrodynamic conditions was analyzed to investigate the sediment transport dynamics. The model's results indicate that the action of tidal currents dominate the sediment deposition and re-suspension in the coastal waters of the East China Sea. This is especially the case in Hangzhou Bay where the tidal currents are strongest. The satellite-derived sediment data product can not only dramatically improve the specification of the initial conditions for the sediment model, but can also provide valuable information for the model validation, thereby improving the model's overall performance.
\end{abstract}

Keywords: suspended sediment; remote sensing; numerical modeling; GOCI; COHERENS; Hangzhou Bay

\section{Introduction}

Coastal waters, especially in estuarine regions, are often characterized by high suspended sediment concentrations derived from both coastal runoff and local sediment re-suspension. In addition, suspended sediments are closely related to construction activity in the marine environment in coastal areas [1]. Because they are one of the major parameters that regulate the optical properties of seawater (e.g., transparence and water color), which impacts on total primary production [2], suspended sediments are also of primary importance to water quality management. Further, because suspended sediment transport accounts for nearly half of the terrigenous organic carbon exported by rivers, it is also a significant factor in the global carbon cycle [3] and biogeochemical cycles [4]. From an management perspective, the transport of suspended sediment is also a prime consideration for the maintenance of the navigation channel, offshore engineering of structures, and the evolution of coastal topography [5]. Therefore, monitoring and observing the distribution and transport of suspended sediments is of significant research and practical value.

In practice, field investigations can obtain an accurate SSC distribution over the entire water column at relatively high temporal frequency. However, they are limited to relatively low spatial 
resolution, and there are some data inconsistencies caused by different sampling times between observation stations [6]. Compared to field investigations, satellite remote sensing combined with numerical modeling can acquire considerably more detailed information about the distribution and transport of suspended sediments. For example, with the remote sensing of ocean color, satellite sensors can provide a near instantaneous view of the large-scale field of suspended sediments with high spatial resolution. However, satellites are limited in that they only acquire data from the ocean surface layer, and can be restricted by excessive cloud cover and/or bad weather conditions [7]. Numerical modeling has the advantage that one can obtain continuous estimates of the three dimensional SSC field, and investigate the SSC responses in environments with different ocean dynamics. But the usefulness of the numerical approach is strongly dependent on the knowledge of oceanic dynamic processes, the correct determination of key parameters in formulations and the quality of initial fields, etc. [8,9]. Therefore, one can combine satellite remote sensing with numerical models to improve the utility of the research for suspended sediment transport and outcomes in coastal waters.

The approach of combining satellite remote sensing with numerical modeling has been widely discussed by many researchers. A number of satellite and airborne remote sensing instruments, such as the Landsat Thematic Mapper (TM) [10,11], the Coastal Zone Color Scanner (CZCS) [6,12], the Advanced Very High Resolution Radiometer (AVHRR) $[13,14]$, the Sea-viewing Wide Field-of-view Sensor (SeaWiFS) [15,16], the Moderate Resolution Imaging Spectroradiometer (MODIS) [17,18], Ocean Colour Monitor (OCM) onboard the Indian Remote Sensing Satellite (IRS-P4) [19] and the Medium-resolution imaging spectrometer (MERIS) [20,21] have been widely used to infer suspended sediment concentration in inland rivers and coastal waters. In most cases, these satellite-derived SSC fields are subsequently integrated into a numerical model for modeling the suspended sediment transport and outcomes. However, due to the limitation on the temporal resolution of the satellite sensors mentioned above, there has been less research on the diurnal variation of SSC using the combined approach.

In the present study, a coupled hydrodynamic-ecological numerical model COHERENS [22] is configured to study the diurnal variation of the SSC in the East China Sea, with a particular focus on the Hangzhou Bay. Firstly, we utilize a snapshot of the GOCI derived SSC to initialize the sediment transport model, and then subsequent modeling results are validated against the temporally evolving satellite SSC data. Finally, a particular phenomenon in the daily change of SSC within Hangzhou Bay is captured by GOCI, and the sediment transport model is used to give an explanation.

\section{Data and Methods}

\subsection{Study Area}

The East China Sea (ECS) is located between the Chinese mainland to the west, Taiwan Strait to the south, the Yellow Sea to the northwest and Japan Sea to the northeast. The ECS is a marginal sea between the West Pacific Ocean and mainland China and covers an area of about $7.7 \times 10^{5} \mathrm{~km}^{2}$. The bathymetry of the study area is shown in Figure 1. The average depth of ECS is about $370 \mathrm{~m}$, with the deepest spot, just to the west side of Okinawa, of about $2700 \mathrm{~m}$. The currents in the East China Sea include the Kuroshio Current, Taiwan Warm Current, Tsushima Warm Current [23], Subei Coastal current, Changiiang Diluted Water and the Yellow Sea Warm Current. Of these, the Kuroshio Current and the Taiwan Warm Current are the main streams flowing into the ECS and the Yellow Sea Warm Current is the primary stream flowing out. While these warm streams flow to the north all year, the magnitude of their transport changes with the seasons. The coastal current is a stream of cold, low salinity water flowing into the ECS. The velocity and direction of the coastal current changes markedly with the seasons. The currents in Hangzhou Bay are tidally-dominated and possesses one of the world's strongest tides. The tidal amplitude typically varies from 3-4 $\mathrm{m}$ at the mouth to $4-6 \mathrm{~m}$ at the head, but a maximum of $9 \mathrm{~m}$ at the head was recorded [24,25]. The average annual water and sediment discharge from the Changiiang River into the ECS are approximately $925 \times 10^{9} \mathrm{~m}^{3}$ 
and $500 \times 10^{6}$ tons, respectively [26]. The primary river discharging water and sediment into the Hangzhou Bay is the Qiantang River, which has an average runoff of $42 \times 10^{9} \mathrm{~m}^{3}$ and an average sediment load of $7.9 \times 10^{6}$ tons annually. These physical features and processes make the ECS one of the more dynamic marginal seas in the world.

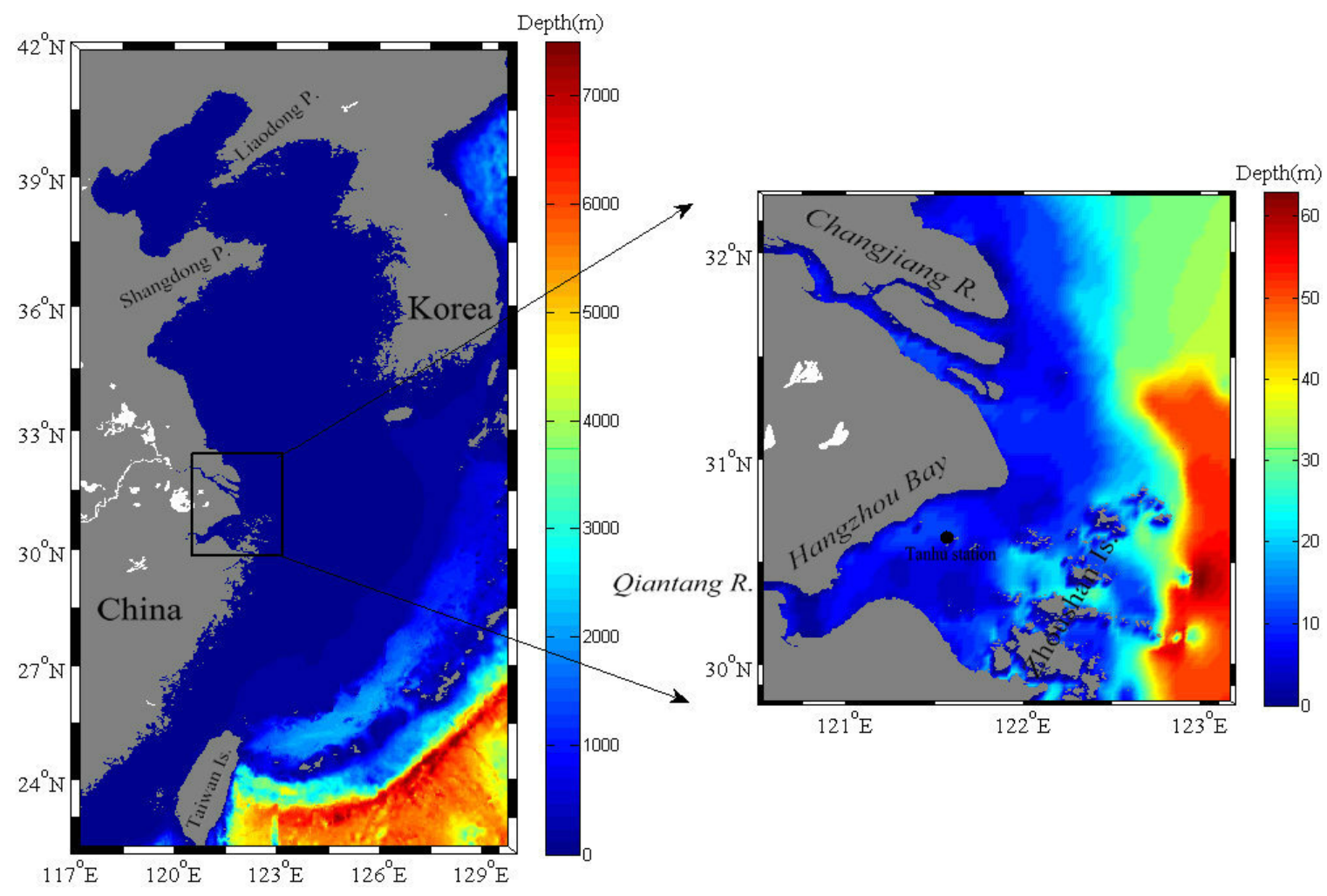

Figure 1. Location map of the study region.

\subsection{Retrieval of SSC from GOCI}

The Geostationary Ocean Color Imager (GOCI) is the world's first ocean color observational satellite placed in geostationary orbit [27]. The monitored region spans from $116.08^{\circ} \mathrm{E}$ to $143.92^{\circ} \mathrm{E}$ and from $24.75^{\circ} \mathrm{N}$ to $47.25^{\circ} \mathrm{N}$, and full coverage of this area is composed of 16 slot images. The GOCI obtains spectral information in 8 wavelength bands, 6 in the visible range and 2 in the near-infrared [28]. Compared with other ocean color satellite imagers, the GOCI has a distinct advantage in time resolution. Because it is geosynchronous, it can obtain satellite data at one hour intervals, which is well suited for monitoring the suspended sediment distribution and transport, and has an especially good resolution of diurnal variations $[29,30]$.

While the UV band can be used to estimate the aerosol scattering reflectance from extremely turbid waters, such as those in Hangzhou Bay, the water-leaving radiance in the UV band is small compared with that in the VIS and NIR bands and can be neglected [31]. In the present study, because GOCI has no UV band, a UV-AC algorithm is used on the GOCI Level-1B data, with the $412 \mathrm{~nm}$ wavelength band used as the reference band for deriving the remote sensing reflectance $\left(R_{r s}\right)$ [31]. Maps of SSC are generated from $R_{r s}$ images using an empirical algorithm based on the observed relationship between in-situ measurements of $R_{r s}$ and SSC. The following algorithm was developed by He et al. [32], and was derived from observations taken by the '908 Project' [32]. It was shown to apply to the SSC range of $8 \mathrm{mg} / \mathrm{L}$ to $5275 \mathrm{mg} / \mathrm{L}$ seen in Hangzhou Bay. For more detailed information 
about the UV-AC algorithm and SSC retrieval algorithm, a full description is presented in He et al. [32]. The resulting algorithm is expressed by the following:

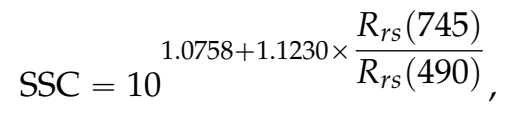

where SSC is the suspended sediment concentration in $\mathrm{mg} / \mathrm{L}$ and $R_{r s}$ are the remotely sensed reflectances at the wavelengths given in the parentheses.

Cloud free GOCI Level-1B data from 29 December 2013 to 1 January 2014 were selected from the Korea Ocean Satellite Center (KOSC) to study the diurnal variation of the suspended sediment concentration in the coastal waters of the East China Sea in general, and in the Hangzhou Bay in particular. Because of the frequency of cloud coverage in this region, this was the longest continuous cloud-free time period in the GOCI data set for the study area. The SSC maps were derived from the GOCI Level-1B data using the same algorithms mentioned above. Seven GOCI images are used to map the SSC distribution in the study area: 3 simultaneous images were acquired at 4:28 p.m. local time on 29, 30 and 31 December 2013, and 4 images were acquired between 02:28 p.m. and 05:28 p.m. local time on 1 January 2014. These GOCI images were taken during the dry season and their timing coincides with the spring tide in Hangzhou Bay.

\subsection{Sediment Transport Modeling}

COHERENS is a three-dimensional, multi-purpose, hydrodynamic numerical model for coastal and shelf seas that is coupled with biological, sediment and contaminant models, and resolves mesoscale and seasonal scale processes [22]. COHERENS was developed by a multinational European group funded by the European Union within the framework of the EU-MAST projects PROFILE, NOMADS, and COHERENS. The model has been used by many researchers in studies including Europe's North Sea, Sacca di Goro in the Adriatic Sea, the Bohai Sea and the Dover strait [33-36].

\subsubsection{Hydrodynamic Module Configuration}

The model domain spans from $29.8^{\circ} \mathrm{N}$ to $32.3^{\circ} \mathrm{N}$ and from $120.5^{\circ} \mathrm{E}$ to $123.2^{\circ} \mathrm{E}$ and is shown in Figure 1. The bathymetry data is a slightly smoothed version of that obtained from the NOAA National Geophysical Data Center (ETOPO1) database. The model's horizontal gird resolution is $500 \mathrm{~m}$, and the water column is divided into 10 vertical sigma levels. The model domain possesses three open sea boundaries located at $32.3^{\circ} \mathrm{N}$ in the north, $29.8^{\circ} \mathrm{N}$ in the south and $123.2^{\circ} \mathrm{E}$ in the east and two river boundaries, including Changjiang River and Qiantang River, that are situated within the coastal boundary in the west.

The meteorological forcing data are extracted from the National Center for Environmental Prediction (NCEP) reanalysis data, which are interpolated to match the model's horizontal grid resolution. These data include the two horizontal wind components at $10 \mathrm{~m}$, air temperature, air pressure, relative humidity, precipitation rate and cloud cover. The time step of meteorological data is set to $6 \mathrm{~h}$.The tides are forced along the three open sea boundaries using eight major tidal constituents, including 4 diurnal tidal constituents $\left(\mathrm{K}_{1}, \mathrm{O}_{1}, \mathrm{P}_{1}\right.$ and $\left.\mathrm{Q}_{1}\right)$ and 4 semidiurnal tidal constituents $\left(\mathrm{M}_{2}, \mathrm{~S}_{2}\right.$, $\mathrm{N}_{2}$ and $\mathrm{K}_{2}$ ), which are derived from the regional ocean tidal model NAO.99Jb. In order to prevent spurious vertical velocities at the open sea boundaries, a zero normal gradient condition is applied at the boundaries to compute the three-dimensional currents.

The boundary conditions for the Changjiang River and Qiantang River are determined through a two-layered stratification construct. The zero normal gradient conditions are applied in the bottom layer and the inputs of fresh water are assigned to the upper layer. The input of the Changjiang River is specified by using monthly averaged runoff at the Datong gauging station. A no-slip condition is applied at the coastal boundaries and there are no advective or diffusive fluxes. 
A spherical coordinate system is selected for the model simulation, with the governing equations discretized on the Arakawa-C grid in the horizontal and a $\sigma$ coordinate in the vertical direction. The more general equation of the state of seawater released by the Joint Panel on Oceanographic Tables and Standards is selected to compute density and buoyancy. The total variation diminishing (TVD) scheme is selected to compute the advection of momentum and scalars with the weight factor given by the specification of the superbee limiting function. All vertical eddy viscosity coefficients in the momentum and scalar equations are evaluated by the ' $\mathrm{k}-\mathrm{l}^{\prime}$-level 2.5-order turbulence closure scheme developed by Mellor and Yamada(1982) [37]. The formulation of Smagorinsky (1963) [38] is used to parameterize the horizontal diffusion coefficients. The bottom stress is evaluated using the quadratic friction law.

We compute the surface stress as a function of the wind components at a reference height of $10 \mathrm{~m}$ to acquire the surface boundary condition for the horizontal current. A quadratic friction law is applied to the slip boundary conditions to calculate the horizontal currents at the bottom using a roughness length of $0.001 \mathrm{~m}$.

The surface flux of temperature is given by

$$
\frac{\rho_{0} c_{\mathrm{p}}}{J} \lambda_{T} \frac{\partial T}{\partial x_{3}}=Q_{s}
$$

where $c_{\mathrm{p}}$ is the specific heat of seawater at constant pressure, $Q_{s}$ is the total downward directed heat flux at the surface. The total flux $Q_{s}$ is composed of the radiative flux $Q_{\text {rad }}$ plus a term for all non-solar contributions $-Q_{n s o l}$.

The non-solar heat flux $Q_{n s o l}$ is composed of three parts:

$$
Q_{n s o l}=Q_{l a}+Q_{s e}+Q_{l w}
$$

where $Q_{l w}$ is the net long-wave radiation emitted at the sea surface, $Q_{s e}$ is the sensible heat flux due to the turbulent transport of temperature across the air-sea interface and $Q_{l a}$ is the latent heat flux released by evaporation.

The surface salinity flux can be calculated by the formula from Steinhorn (1991) [39]:

$$
\rho_{0} \frac{\lambda_{T}}{J} \frac{\partial S}{\partial x_{3}}=\frac{S_{s}\left(E_{v a p}-R_{p r}\right)}{1-0.001 S_{S}}
$$

where $S_{\mathrm{s}}$ is the surface salinity in PSU, $R_{p r}$ is the precipitation rates in $\mathrm{kg} \cdot \mathrm{m}^{-2} \cdot \mathrm{s}^{-1}$ and $E_{v a p}=Q_{l a} / L_{v}$ is the evaporation rate in $\mathrm{kg} \cdot \mathrm{m}^{-2} \cdot \mathrm{s}^{-1}$.

The open sea boundaries are constrained monthly by vertical profiles of temperature and salinity provided by World Ocean Atlas (WOA) 2013. Zero flux conditions are applied at the bottom boundary for both temperature and salinity. The model initialization time is in winter, and the strong tide-induced mixing makes the salinity and temperature uniform over the whole water column in the entire simulated domain [40]. Therefore the salinity and temperature field are uniformly set at 30 PSU and $5{ }^{\circ} \mathrm{C}$ respectively, which are reasonable values for the wintertime coastal waters of ECS.

The model is run with an external model time step of $6 \mathrm{~s}$ and an internal model time step of $60 \mathrm{~s}$, which satisfies the Courant-Friedrichs-Lewy (CFL) criterion. The model starts in a state of rest and the spin-up run takes one year (1 January 2013 to 28 December 2013) ensuring that the model reaches a quasi-steady state. At the end of the hydrodynamic model spin-up time, the sediment model is coupled with the hydrodynamic model to simulate the suspended sediment transport in coastal waters of the ECS in general and in Hangzhou Bay in particular. 


\subsubsection{Sediment Module Configuration}

The sediment transport model is configured to run fully coupled to the hydrodynamic model. The governing equation for the suspended sediment transport model is:

$$
\frac{\partial C}{\partial t}+\frac{\partial}{\partial x}(C u)+\frac{\partial}{\partial y}(C v)+\frac{\partial}{\partial z}\left(C\left(w-w_{s}\right)\right)=\frac{\partial}{\partial x}\left(\lambda_{H} \frac{\partial C}{\partial x}\right)+\frac{\partial}{\partial y}\left(\lambda_{H} \frac{\partial C}{\partial y}\right)+\frac{\partial}{\partial z}\left(\lambda_{H} \frac{\partial C}{\partial z}\right),
$$

where $(u, v, w)$ is the 3 components of the current, $w_{s}$ is the sinking rate of suspended sediment, $t$ is the time, $C$ is the suspended sediment concentration and $\lambda_{T}$ and $\lambda_{H}$ are the vertical and horizontal diffusion coefficients for suspended sediments, respectively.

Suspended sediments are advected and diffused throughout the water column by the currents from the hydrodynamic model. In addition, suspended sediments may also be transported vertically by sinking and/or re-suspension from the seabed. The SSC is not only related to the bed shear stress driven by the near bed currents but also to the local water depth and the sediment type [41]. The main bottom sediment types and their distribution patterns are shown in Figure 2 [42]. The ocean bottom of the ECS is dominated by a submarine delta occupying most of the inner shelf. The inner shelf is covered with silty clay to the south of the Changjiang River [26,43] and silty, clay-like fine sands to the north. The silty clay results from the accumulation of Changjiang River sediments, while the silty, clay-like sands are mostly derived from the old Yellow River. Sediments in the Hangzhou Bay are predominantly composed of fine and medium silt, with an averaged grain size less than $0.038 \mathrm{~mm}$ and are vertically well-mixed [44-46].

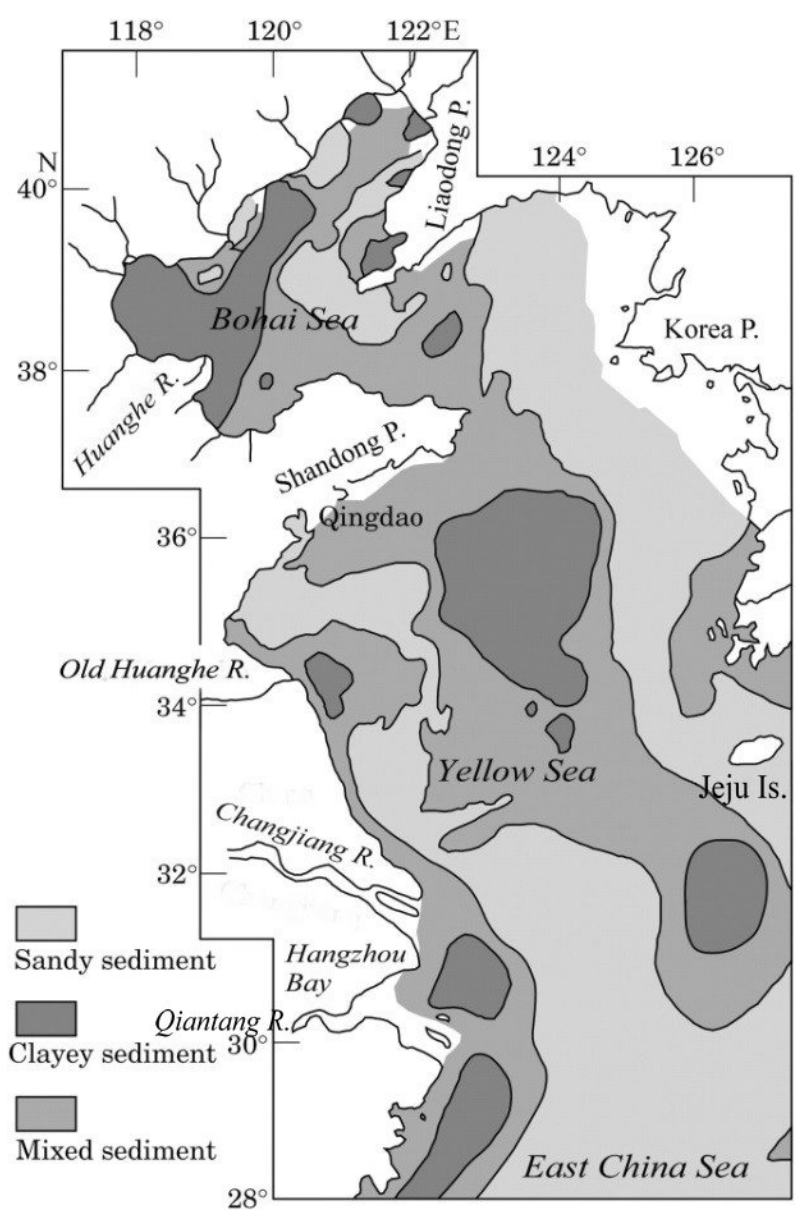

Figure 2. The main bottom sediment types and their distribution patterns in the ECS (modified from Zhu and Chang, 2000 [42]). 
The sinking rate of suspended sediments varies with particle size, shape and relative density. In the study area, the suspended sediments consist mainly of fine particulate material and very fine suspended sediments released by the Changjiang River and Qiantang River [25,42-46]. Beginning with the reference settling velocity of $0.0002 \mathrm{~m} / \mathrm{s}$ given by Ramakrishnan and Rajawat [8], a uniform particle sinking rate $0.0006 \mathrm{~m} / \mathrm{s}$ for suspended sediments is arrived at after model calibration. This settling velocity is passed to the hydrodynamic model and particle sinking is implemented in the advection-diffusion equation through an additional advection term in the vertical transport equation.

Resuspension transfers previously deposited sediments from the seabed into the water column. These resuspended sediments are reintegrated with the existing sediment population in the water column and are then subject to advection, diffusion and sinking. The flux of suspended sediments being eroded from the sea bed and re-suspended in the water column is given by the erosion rate $E(C)$ (amount $\mathrm{mg} \cdot \mathrm{m}^{-2} \cdot \mathrm{s}^{-1}$ ):

$$
E(C)=\alpha_{s}\left|\frac{\tau_{100}}{\tau_{b, r e f}}\right|^{n_{s}},
$$

where $C$ is the suspended sediment concentration, $\tau_{100}$ is the shear stress at a reference height of $1 \mathrm{~m}$, $\alpha_{s}$ and $n_{s}$ are adjustable fitting parameters with values of $0.0025 \mathrm{~g} \cdot \mathrm{m}^{-2} \cdot \mathrm{s}^{-1}$ and 3.0 , respectively and were taken from Jones et al., (1996) [47] and $\tau_{b, r e f}$ is the bottom critical shear stress whose value is set to $0.1 \mathrm{~N} \cdot \mathrm{m}^{-2}$. The shear stress $\tau_{100}$ is obtained by:

$$
\tau_{100}=\rho_{0} C_{100}\left(u_{100}^{2}+v_{100}^{2}\right),
$$

where $\left(u_{100}^{2}+v_{100}^{2}\right)$ are the linearly interpolated values of the horizontal components of current at $1 \mathrm{~m}$ above the seabed. The bottom friction coefficient at the reference height $C_{100}$, which includes the effects of wave-current interactions, is determined by:

$$
C_{100}=\left(\frac{k}{\ln \left(30 / k_{b c}\right)}\right)^{2},
$$

where $k$ is von Karman's constant $(=0.4), k_{b c}$ is the apparent bottom roughness, which is a local variable used to evaluate the bottom drag coefficient.

Because sediment cannot escape through the free surface, there is a no flux surface boundary condition in the sediment transport model. In addition, zero sediment gradient conditions are imposed at all open sea boundaries and a scalar condition is applied to the river boundaries. The input of the Changiiang River is specified by using the monthly averaged discharge at the Datong gauging station, which were extracted from the Changjiang Sediment Bulletins from 2013 and 2014. The discharge data of the Qiantang River were obtained from the River Regime Bulletion of the Tai Lake Basin from 2013 and 2014. The total sediment transport data for the Changjiang and Qiantang Rivers were computed from the GOCI derived SSC at one hour intervals multiplied by the river discharge.

\section{Results and Discussion}

\subsection{Sediment Model Initialization and Validation}

The quality of any sediment transport simulation is related to many factors, of which the accurate specification of the initial distribution of SSC is extremely important [48]. Due to a lack of sufficient observational data, previous researchers have had to either assume that the initial field of SSC is uniformly distributed over the entire model domain, or use sparse measurements of SSC to specify the distribution throughout the model domain, by employing various interpolation methods. In the present study, we used a GOCI derived SSC field as the initial condition for the sediment model in the simulation of the diurnal variation in SSC in Hangzhou Bay. Specifying the initial field of SSC by using GOCI data provides a general distribution over the entire domain that is closer to the real 
distribution than any of the methods above [49]. Figure 3 shows the surface SSC distribution retrieved from cloud free GOCI data acquired at 4:28 p.m. on 29, 30 and 31 December 2013 that were used to initialize and validate the sediment transport model. The specification of an appropriate vertical distributon for the initial SSC in the numerical model, is considered a difficult problem. Because the model simulation is initialized in winter, at a time of strong vertical tidal mixing, adopting a uniform sediment concentration throughout the water column is a reasonable assumption. Therefore, the initial SSC field in the model is specified by the GOCI-derived surface SSC from 4:28 p.m., 29 December 2013, interpolated to the model's horizontal grid and projected downward over the water column.

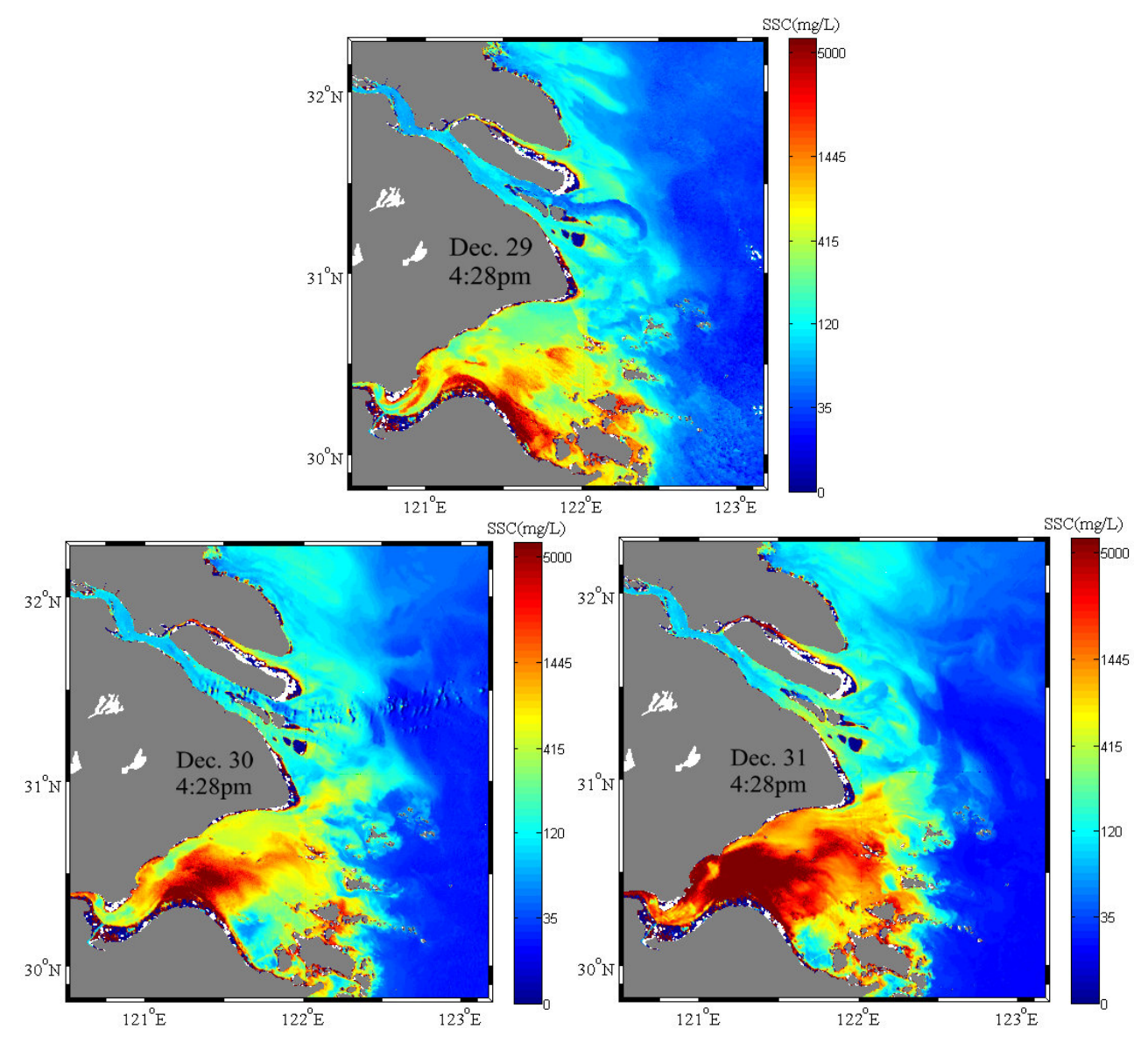

Figure 3. Surface SSC (mg/L) in the study area derived from GOCI satellite data at 4:28 p.m., 29 December 2013 for model initialization and at 4:28 p.m., 30 and 31 December 2013 for model validation.

After initializing the sediment concentration for the numerical simulation, the spun-up model is run for 2 days to calculate the SSC distribution and transports at 4:28 p.m. on 30 and 31 December of 2013, when the other two cloud free GOCI derived SSC images (in Figure 3) were taken. The temporal and spatial variation of the SSC is not only an important manifestation of the sediment transport, but also a consequence of the hydrodynamic and meteorological conditions and the regional characteristics of the study area. Aiming to validate the performance of the sediment transport model, we consider the GOCI derived SSC to be the truth, and then computed the difference between the modeled and the GOCI derived SSC. Maps of modeled SSC at 4:28 p.m., 30 and 31 December 2013 are extracted from the sediment transport model and are shown in Figure 4. Compared with the corresponding GOCI derived SSC images in Figure 3, the simulation results show that the concentration and distribution of suspended sediments in Hangzhou Bay appear to be consistent with that of the satellite data. We subtract the values of the GOCI derived SSC from the corresponding values of modeled SSC to 
quantitatively evaluate the model performance and the results are presented in Figure 5. The blue areas in this figure are where the simulation results nearly match the observed GOCI field. The maximum difference between modeled SSC and satellite data is less than $1000 \mathrm{mg} / \mathrm{L}$. These results show that the absolute relative errors between modeled SSC and GOCI derived SSC do not exceed 20\%. Figure 5 shows that the SSC are overestimated in Hangzhou Bay by the sediment transport model. A possible reason for this might be that flocculation effects, not included in the model, play an important role in affecting the settling velocity of suspended sediment, and thus affects the suspended sediment distribution in Hangzhou Bay. Given this limitation, the modeled SSC agrees well with the satellite derived SSC, which indicates that the sediment transport model is capable of monitoring the diurnal variation of the SSC in Hangzhou Bay.

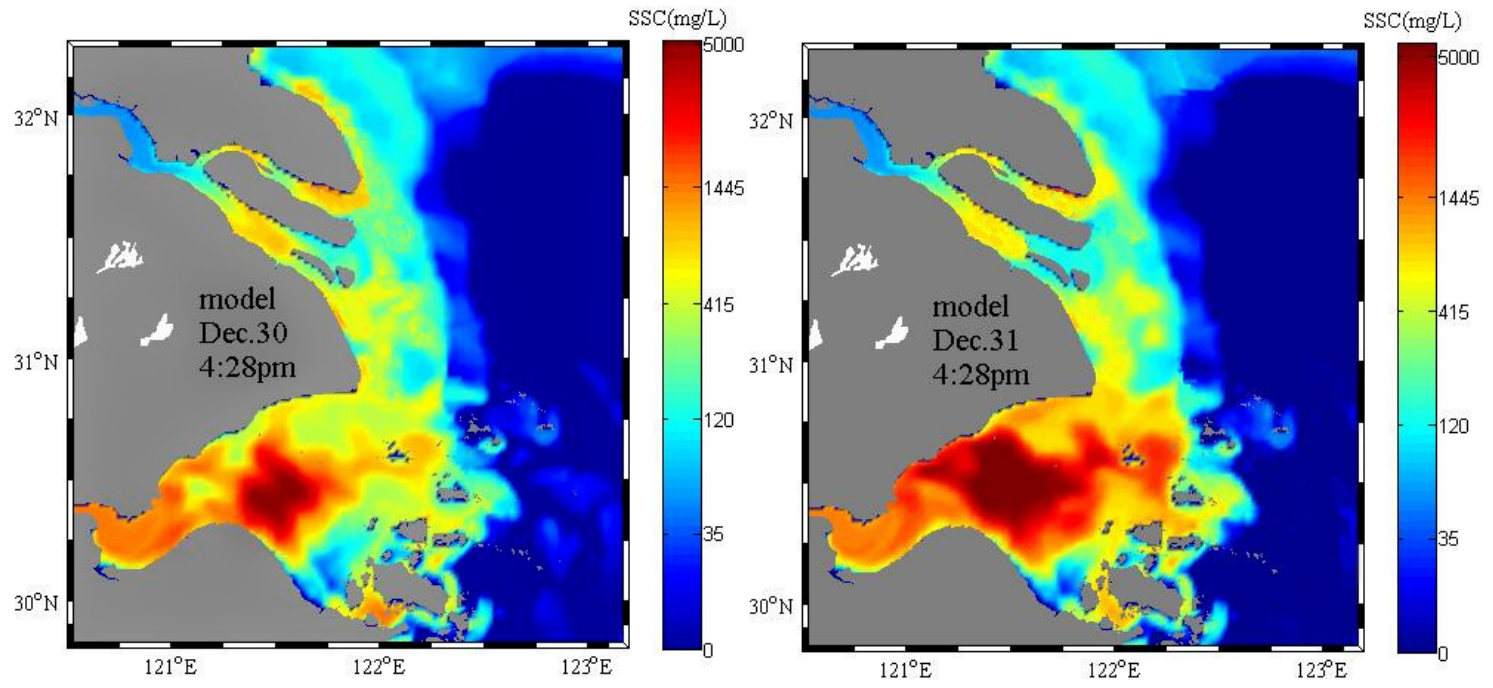

Figure 4. Modeled surface SSC (mg/L) in the study area at 4:28 p.m. on 30 and 31 December 2013.

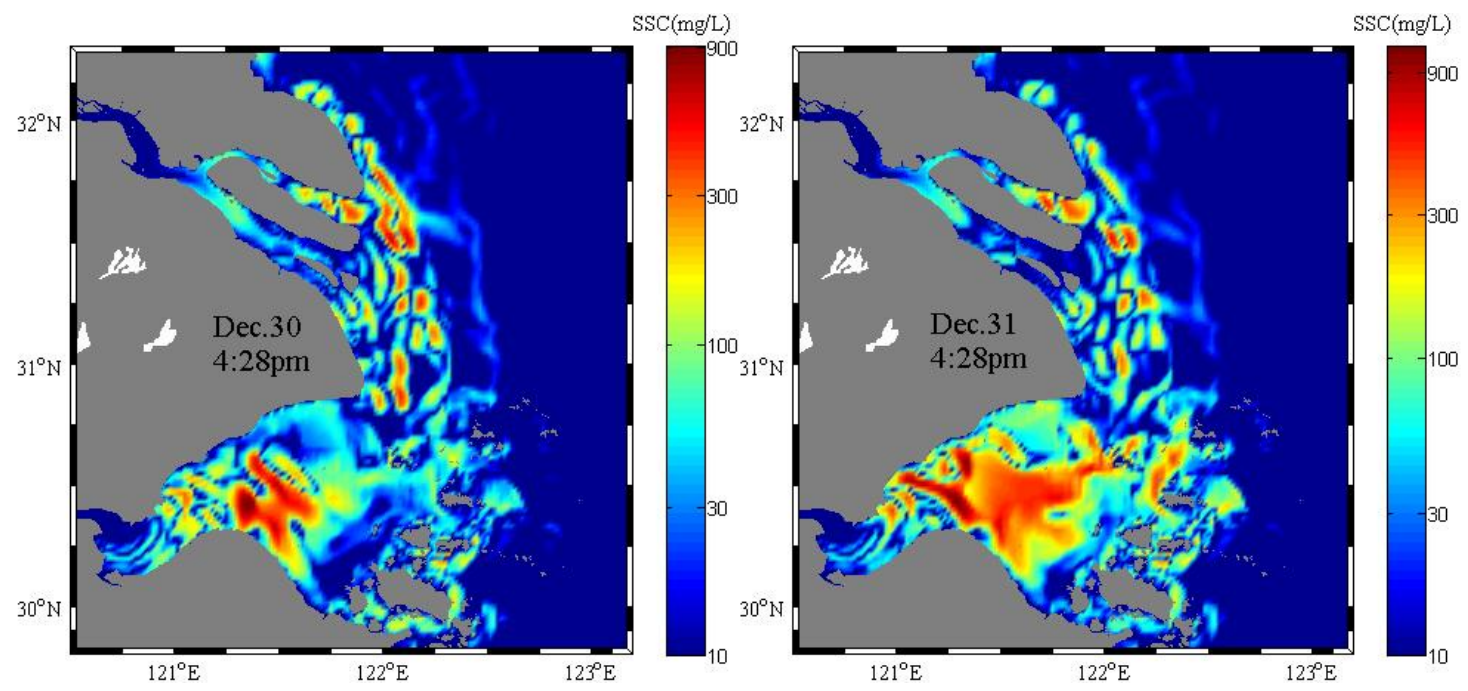

Figure 5. The difference in surface SSC $(\mathrm{mg} / \mathrm{L})$ between the GOCI derived and modeled SSC at 4:28 p.m. on 30 and 31 December 2013 for model validation.

\subsection{The Diurnal Variation of Suspended Sediment}

After validating the sediment model's performance, the model was run to simulate the evolution of the SSC distribution and transport. Maps of SSC obtained from the sediment transport model at 2:28 p.m., 3:28 p.m., 4:28 p.m. and 5:28 p.m. on 1 January 2014 are compared with the corresponding 
GOCI derived SSC images and shown in Figure 6. Through the comparison between the simulation results and satellite derived images, it is clear that the surface SSC values in the study area are universally high in coastal zone, even reaching around $5000 \mathrm{mg} / \mathrm{L}$ in the middle of Hangzhou Bay, and are lower offshore to the east of $122.5^{\circ} \mathrm{E}$. This is consistent with the overall features of suspended sediment distribution in the ECS. The comparison between the observed and modeled SSC fields indicates that the sediment transport model can reproduce the basic distribution of suspended sediment in the coastal waters of the ECS.

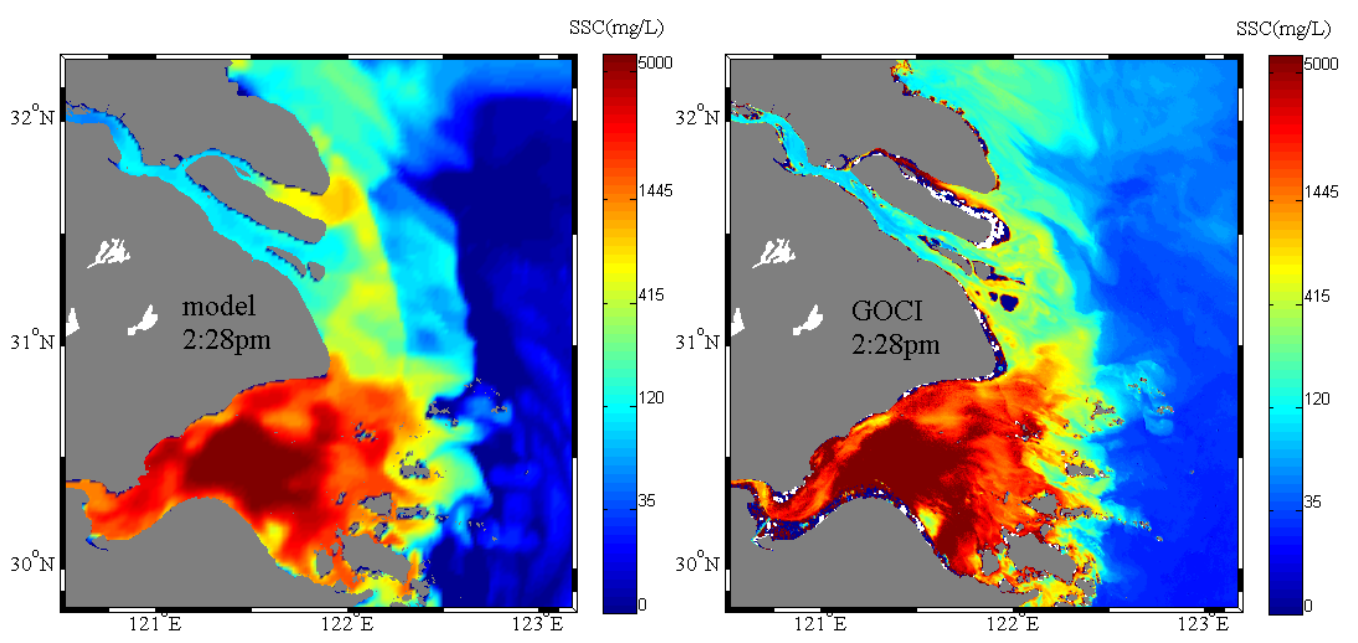

$\mathrm{SSC}(\mathrm{mg} / \mathrm{L})$
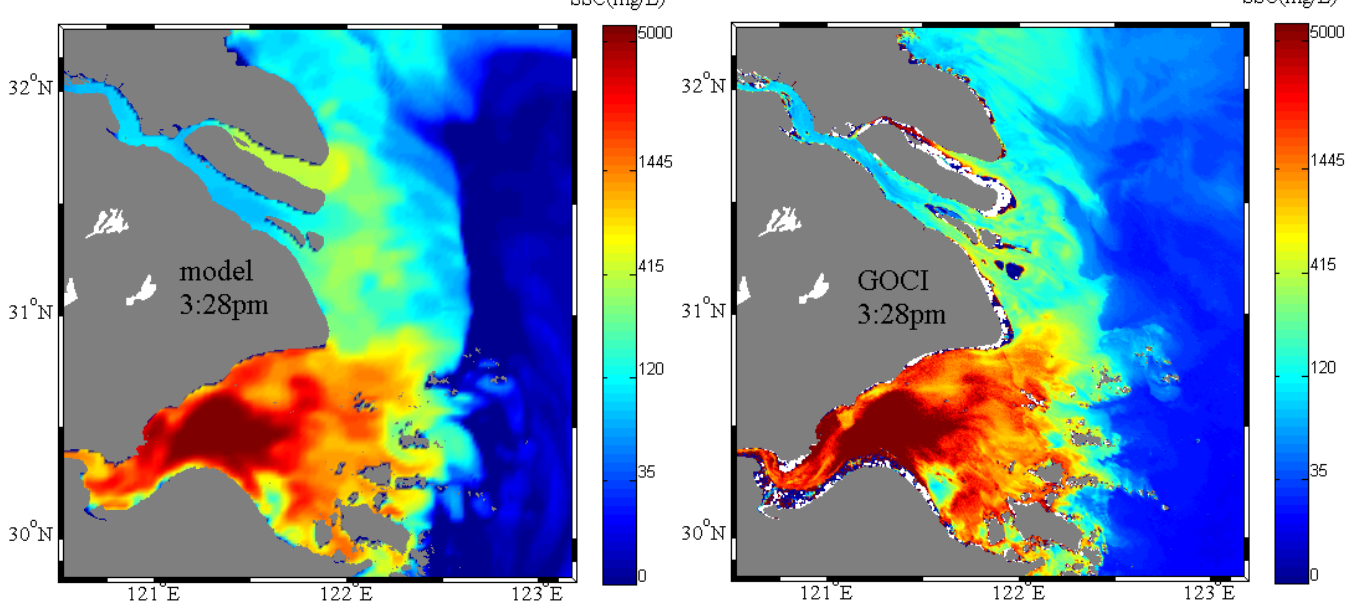

$\mathrm{SSC}(\mathrm{mg} / \mathrm{L})$
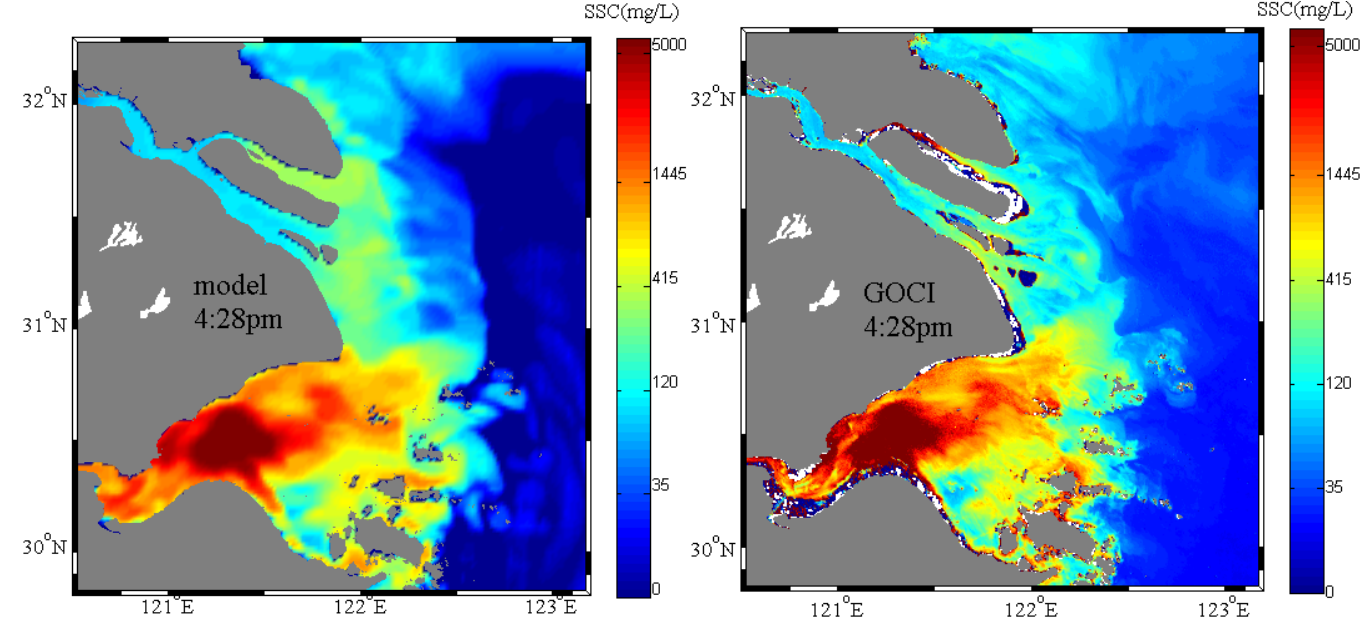

Figure 6. Cont. 


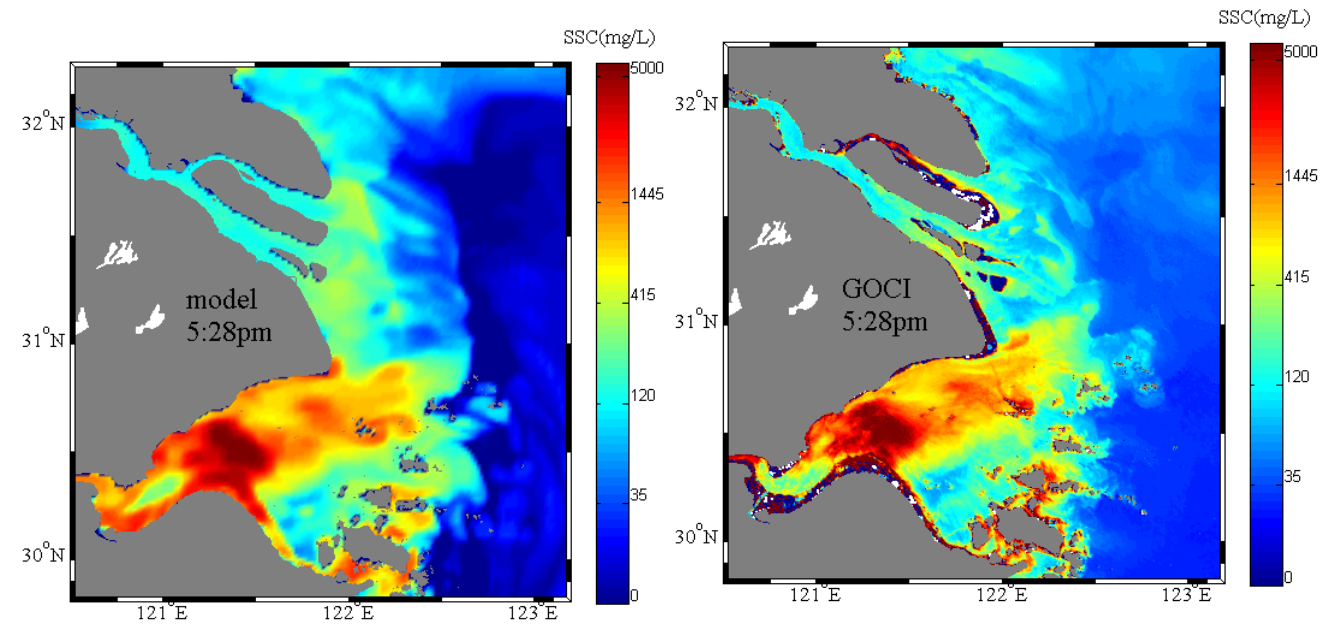

Figure 6. Comparison of simulated surface SSC with GOCI derived SSC (mg/L) on 1 January 2014.

In order to further validate the reliability of sediment transport model, a statistical analysis is performed and summarized in the scatter plots shown in Figure 7. The root mean square errors (RMSE) are 1682, 1482, 1473 and $1831 \mathrm{mg} / \mathrm{L}$ for 2:28 p.m., 3:28 p.m., 4:28 p.m. and 5:28 p.m., respectively. As can be seen by the clustering about the 1:1 line in these results, the modeled SSC results are in basic agreement with the satellite derived SSC. A possible reason for the relatively large RMSE differences (1682 and $1831 \mathrm{mg} / \mathrm{L})$ might be that shallow water and flocculation effects have impacts on the sediment distribution in the extremely turbid Hangzhou Bay. The statistical results further indicate that the sediment transport model can effectively reproduce the spatial and temporal variation of the SSC in the coastal waters of the ECS.
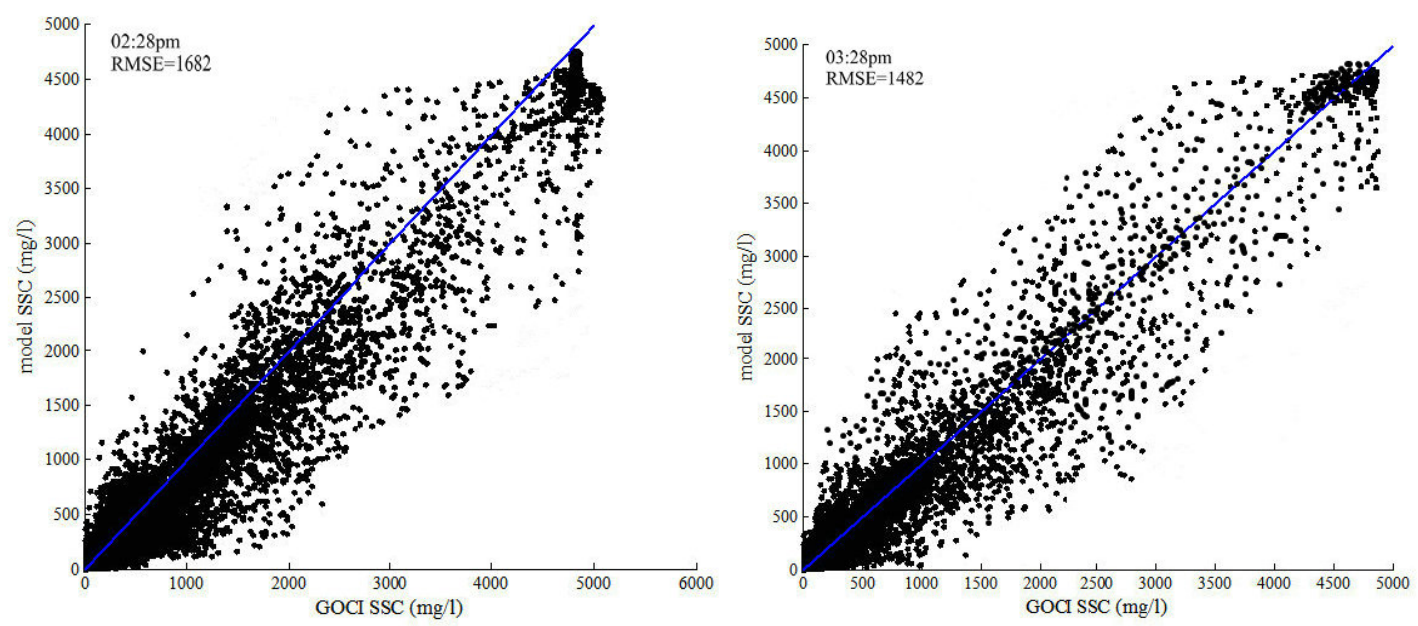

Figure 7. Cont. 

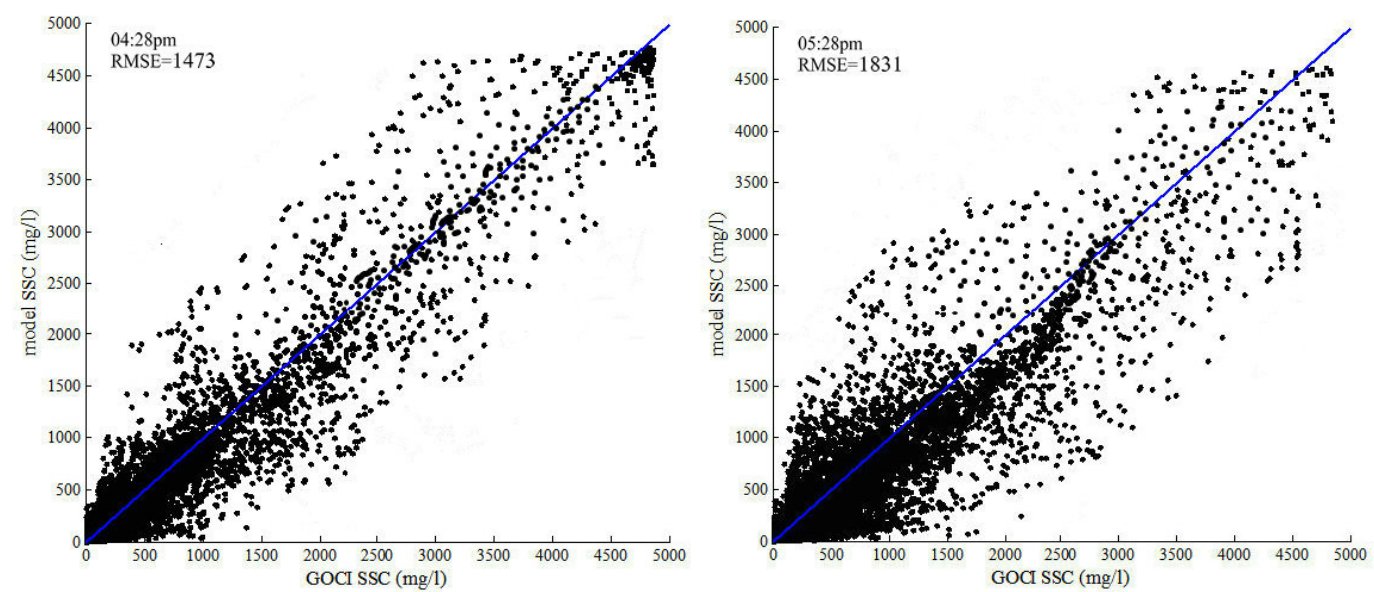

Figure 7. Scatter plots showing the comparison of individual simulated surface SSC with GOCI-derived SSC.

In Figure 6, a gradual decrease in the SSC values in time are observed from both the GOCI-derived and simulation results, especially in Hangzhou Bay. Temporal and spatial variations of SSC are a consequence of the hydrodynamic conditions, model forcing, sediment inputs and the regional characteristics of the study area. The monthly averaged runoff of Qiantang River $\left(856 \mathrm{~m}^{3} / \mathrm{s}\right)$ and daily averaged wind velocity $(6 \mathrm{~m} / \mathrm{s}$ from the northeast) are imposed on the model on 1 January 2014 . Therefore, it is assumed that the influence of river runoff and wind field on the SSC distribution and transport will be the same as on 1 January 2014. The temporal and spatial variations of the SSC in Hangzhou Bay are primarily associated with the variations in tidal currents. In Figure 8, the time series of tidal elevation at the Tanhu tide gauge station $\left(30^{\circ} 37^{\prime} \mathrm{N}, 121^{\circ} 37^{\prime} \mathrm{E}\right)$ located in the northern side of Hangzhou Bay, shows that the tidal level drops from about $3.5 \mathrm{~m}$ to about $1.1 \mathrm{~m}$ from 2:28 p.m. to 5:28 p.m. on 1 January 2014. The surface flow field from the numerical simulation corresponding to the times that the GOCI derived SSC images are taken, shown in Figure 9. It's clear that the current direction in Hangzhou Bay is from west to the east, typical of an ebbing tide.

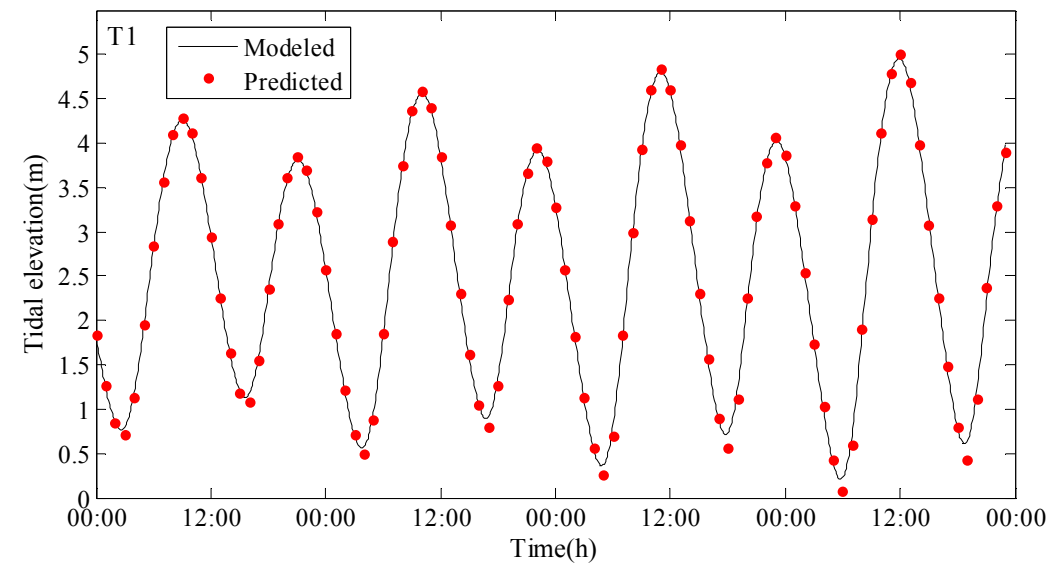

Figure 8. Comparison of modeled and predicted tidal elevation at Tanhu gauge station $\left(30^{\circ} 37^{\prime} \mathrm{N}\right.$, $121^{\circ} 37^{\prime}$ E) from 29 December 2013 through 1 January 2014. 

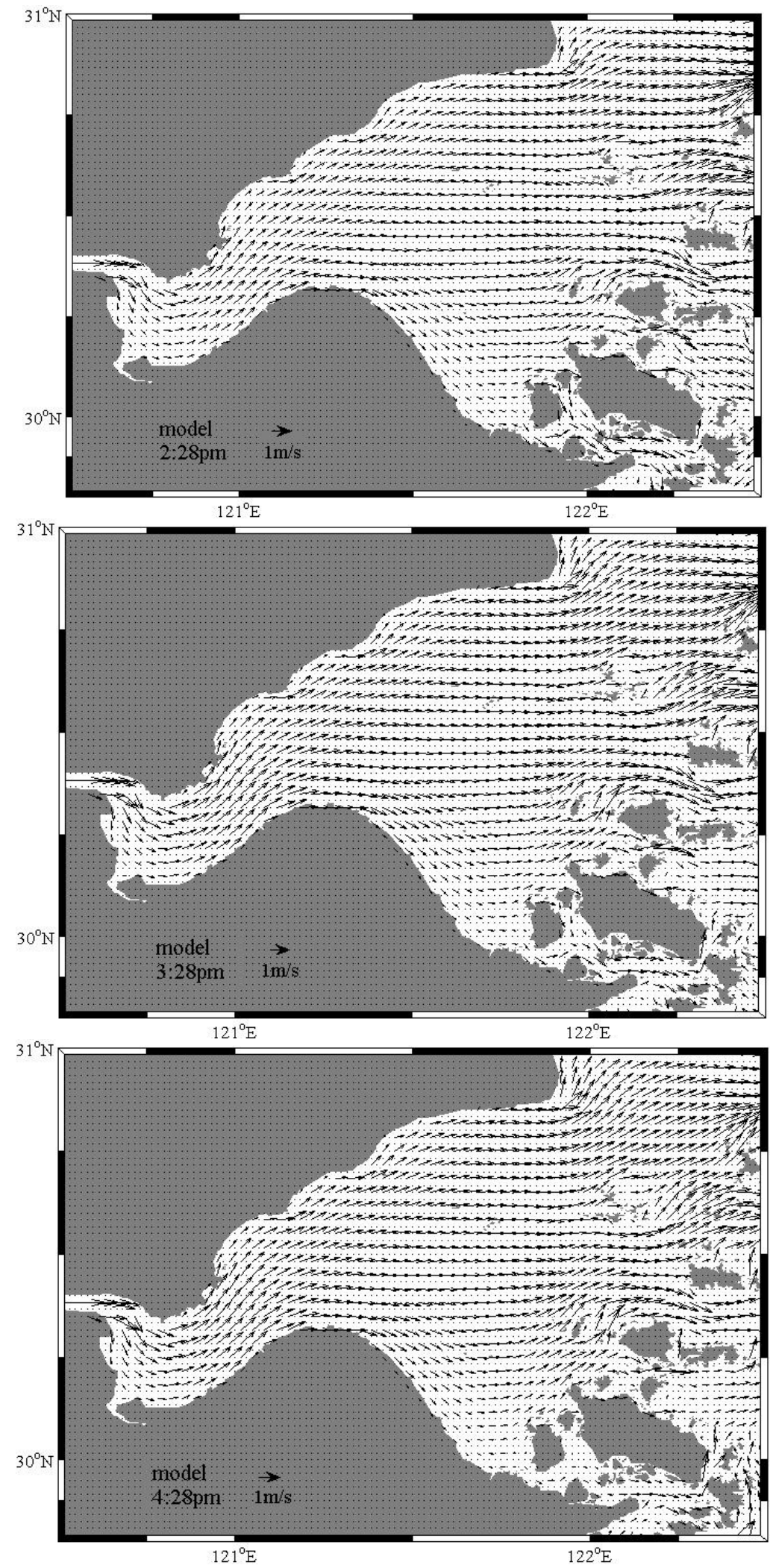

Figure 9. Cont. 


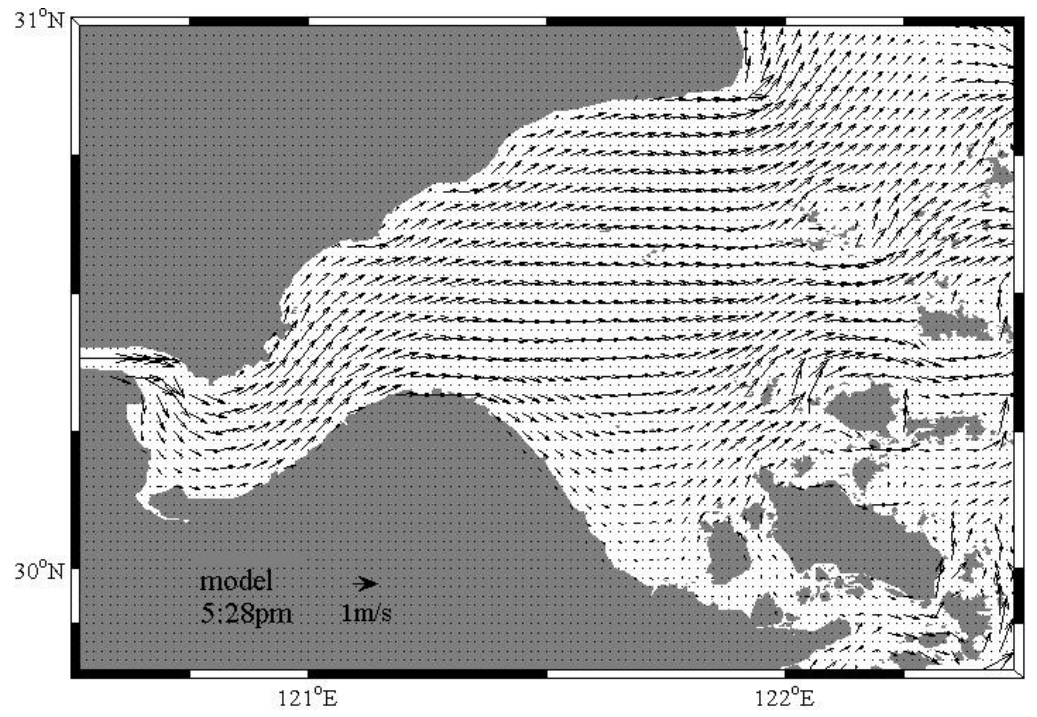

Figure 9. The surface flow field from the numerical simulation corresponding to times that the GOCI derived SSC images on 1 January 2014 were obtained.

Figure 9 shows that the current velocity gradually decreases with simulation time as the tide approaches slack water, which is especially pronounced on the southern side of Hangzhou Bay. A current velocity measuring station at $\left(30^{\circ} 7.4^{\prime} \mathrm{N}, 121^{\circ} 49.5^{\prime} \mathrm{E}\right)$ located on the southern side of the Hangzhou Bay also shows that the flow reduced from about $1.6 \mathrm{~m} / \mathrm{s}$ to about $0.8 \mathrm{~m} / \mathrm{s}$ from 2:28 p.m. to 5:28 p.m. on 1 January 2014. Comparing the variation of flow field with the variation of the SSC in Figure 6, it's apparent that suspended sediment concentration is higher when current velocity is higher. As the current velocity reduces, the suspended sediment concentrations also reduce. High velocity tidal currents trigger re-suspension of previously deposited sediments, resulting in high values of SSC at the times of high tidal velocity in Hangzhou Bay. Likewise, the reduction of current velocity towards the end of the ebb tide allows for the deposition of suspended sediments in Hangzhou Bay. The simulation results reflect that the SSC variations are mainly induced by tidal current, and these results agree well with GOCI derived images and observed data.

Patches of lower SSC on the southern side of Hangzhou Bay and higher SSC in the channels between the Zhoushan Islands are also observed in both the GOCI images and simulation results on 1 January 2014. It appears from the simulation results presented in Figure 9, that this may be due to the blocking effect of Zhoushan Islands that restricts the current velocity on the southern side of Hangzhou Bay. However, the current velocity is still higher between and along the Zhoushan Islands. Due to the large current velocity at 2:28 p.m., the bottom sediments are resuspended under the action of bottom shear stress. Furthermore, because of the strong tidal mixing, the resuspended sediment is mixed rapidly from the bottom to the surface, so that the distribution of suspended sediments is relatively uniform in the vertical direction. When the tidal current velocity decreases as the tide slackens, the bottom shear stress is insufficient to resuspend sediments. It is very hard for the re-suspended sediments to rise to the sea surface in such lower current velocity conditions during the ebb tide. The surface SSC decreases gradually due to sediment deposition as the currents weaken. As can be seen from Figure 9, the current velocity on the southern side of Hangzhou Bay decrease faster than those on the northern side, and the weaker currents on the southern side lead to weaker turbulence. This in turn leads to vertical water motions that would normally oppose sediment settling, making the surface SSC lower on the southern side than those on the northern side. However, the higher velocity between and along the Zhoushan Islands, triggers the resuspension of sediments from the bottom leading to the higher SSC that occurs in this region. 


\subsection{Improvements of Model/Satellite Comparisons}

Although the overall match is good, there are still some differences between model results and satellite images. The derivation of SSC from satellite observations still has some difficulties so that the measurement of sediment concentration isn't perfect. The remote sensing retrieval of suspended sediment concentration is based on the relationship between remote sensing reflectance and suspended sediment concentration. This relationship still needs to be improved to increase the accuracy of atmospheric correction and empirical inversion algorithms. The average relative bias in the empirical inversion algorithm are $13.3 \%$ and $14.2 \%$ and the absolute relative errors are $25.2 \%$ and $56.0 \%$ for SSC $\leqslant 300 \mathrm{mg} / \mathrm{L}$ and SSC $>300 \mathrm{mg} / \mathrm{L}$, respectively [32]. The results showed a relatively small prediction error in the GOCI derived SSC when its concentration was smaller than $300 \mathrm{mg} / \mathrm{L}$, but had a relatively large error when its concentration exceeded $300 \mathrm{mg} / \mathrm{L}$. A reasonable explanation for this relatively large difference is that the sediment types in Hangzhou Bay are naturally complicated. Due to lack of in-situ data from this region, it is hard to determine the sediment's composition, size and shape [32]. In addition, measurement errors, including time differences between reflectance measurement and SSC sampling, water volume measurement, weighting and sedimentation in the sampling bottles might be another reason for some of the discrepancies [32]. Suspended sediment modeling is based on the variations of dynamic marine environments in both the hydrodynamic and sediment transport models as described by the governing equations. However, both the hydrodynamic and sediment transport models are simplified representations of the real coastal water environments, but this simplification makes it easier to analyze and better understand the suspended sediment transport.

Since the operational running of a real-time monitoring and accurate forecast system are the ultimate goal for the suspended sediment research, further work is needed to improve the accuracy of the coupled numerical model. The simulation accuracy is limited by many factors, such as the degree of model sophistication itself, the quality of model inputs, the selection of appropriate parameters for a particular sea area, etc. In the present study, we have tried to optimize the initial conditions for the SSC and validate the model results by comparing the coincident GOCI derived SSC, and have achieved reasonably good results. This is likely because the comparison was established in tidally dominated conditions. A follow-up study will test the model performance under wind dominated conditions and during storm events.

The final issue to consider is that fluid density is an important parameter for calculating settling velocities and resuspension rates in sediment transport. In general, the state equation is used to calculate the fluid density as function of the water temperature and salinity. However, when sediment is present, an additional effect of the particle density of the sediment fraction on the mixed net fluid density, should be considered. In this study, the surface SSC in Hangzhou Bay was extremely high (up to $5000 \mathrm{mg} / \mathrm{L}$ ). It is likey that due to the higher density of sediment relative to water and that near the bed, the SSC are higher. More importantly, the settling velocity of fine grained cohesive sediments is significantly affected by flocculation effects [50], which are not included in the present sediment model. Furthermore, the vertical sediment structure likely leads to a damping of turbulence, which increases the critical bottom shear stress and affects the settling velocity of the sediment, which in turn affects the suspended sediment distribution and net sediment transport. However, this influence has not been taken into account in the existing sediment transport model, and it may be one of the main causes for the differences between the model results and satellite images.

\section{Conclusions}

The present study has demonstrated how two technologies-satellite remote sensing and numerical simulation - can come together to provide an effective tool for investigating the distribution and dynamic changes of ocean water quality parameters, such as the diurnal variation of suspended sediment concentration. Maps of suspended sediment concentration derived from the GOCI imager are used to define the initial field and to validate simulated results from a sediment transport model, which is configured to study the diurnal variation of SSC in the coastal waters of the ECS. The 
statistical analysis comparing the simulated and GOCI derived SSC results shows that, as configured, the sediment transport model provides a reasonably powerful tool for sediment transport modeling. In this study, obvious deposition and re-suspension processes controlled by the strength of the varying tidal currents in Hangzhou Bay are observed both in the modeled and remote sensing results.

The accuracy of initial field is one of the major constraining factors in the development of numerical simulation. Integrating satellite derived products into a numerical model to address this problem was found to be effective. However, the accurate determination of key model processes, especially the key parameters in the physical formulations, is another constraining factor to model performance, and it is necessary to do more in-depth research into these formulations to improve the performance of the sediment transport model coupled with satellite data in the future.

Acknowledgments: The authors gratefully acknowledge the financial support by the National Science Foundation of China (41476156, 41321004) and Public Science and Technology Research Funds Projects of Ocean (201005030). We also thank the editors and reviewers for their insightful remarks.

Author Contributions: Xuefei Yang and Zhihua Mao conceived and designed the research, Xuefei Yang collected satellite data and performed the experiments and analyzed the results.The manuscript was drafted by Xuefei Yang and revised by Zhihua Mao, Haiqing Huang and Qiankun Zhu.

Conflicts of Interest: The authors declare no conflict of interest.

\section{References}

1. Mao, Z.; Chen, J.; Pan, D.; Tao, B.; Zhu, Q. A regional remote sensing algorithm for total suspended matter in the East China Sea. Remote Sens. Environ. 2012, 124, 819-831. [CrossRef]

2. Doxaran, D.; Froidefond, J.-M.; Castaing, P.; Babin, M. Dynamics of the turbidity maximum zone in a macrotidal estuary (the Gironde, France): Observations from field and MODIS satellite data. Estuar. Coast. Shelf Sci. 2009, 81, 321-332. [CrossRef]

3. Schlünz, B.; Schneider, R.R. Transport of terrestrial organic carbon to the oceans by rivers: Re-estimating flux- and burial rates. Int J. Earth Sci. 2000, 88, 599-606. [CrossRef]

4. Yeshaneh, E.; Eder, A.; Blöschl, G. Temporal variation of suspended sediment transport in the Koga catchment, North Western Ethiopia and environmental implications. Hydrol. Process. 2014, 28, 5972-5984. [CrossRef]

5. Chatanantavet, P.; Lamb, M.P. Sediment transport and topographic evolution of a coupled river and river plume system: An experimental and numerical study. J. Geophys. Res. F: Earth Surf. 2014, 119, 1263-1282. [CrossRef]

6. Puls, W.; Doerffer, R.; Sundermann, J. Numerical simulation and satellite observations of suspended matter in the North Sea. Ocean. Eng. IEEE J. 1994, 19, 3-9. [CrossRef]

7. Doxaran, D.; Lamquin, N.; Park, Y.-J.; Mazeran, C.; Ryu, J.-H.; Wang, M.; Poteau, A. Retrieval of the seawater reflectance for suspended solids monitoring in the East China Sea using MODIS, MERIS and GOCI satellite data. Remote Sens. Environ. 2014, 146, 36-48. [CrossRef]

8. Ramakrishnan, R.; Rajawat, A.S. Simulation of suspended sediment transport initialized with satellite derived suspended sediment concentrations. J. Earth Syst. Sci. 2012, 121, 1201-1213. [CrossRef]

9. Guillou, N.; Rivier, A.; Gohin, F.; Chapalain, G. Modeling Near-Surface Suspended Sediment Concentration in the English Channel. J. Mar. Sci. Eng. 2015, 3, 193-215. [CrossRef]

10. Jensen, J.R.; Kjerfve, B.; Ramsey, E.W.; Magill, K.E.; Medeiros, C.; Sneed, J.E. Remote sensing and numerical modeling of suspended sediment in Laguna de Terminos, Campeche, Mexico. Remote Sens. Environ. 1989, 28, 33-44. [CrossRef]

11. Ouillon, S.; Douillet, P.; Andréfouët, S. Coupling satellite data with in situ measurements and numerical modeling to study fine suspended-sediment transport: A study for the lagoon of New Caledonia. Coral Reefs 2004, 23, 109-122.

12. Pleskachevsky, A.; Gayer, G.; Horstmann, J.; Rosenthal, W. Synergy of satellite remote sensing and numerical modeling for monitoring of suspended particulate matter. Ocean Dyn. 2005, 55, 2-9. [CrossRef]

13. Gerritsen, H.; Vos, R.J.; van der Kaaij, T.; Lane, A.; Boon, J.G. Suspended sediment modelling in a shelf sea (North Sea). Coast. Eng. 2000, 41, 317-352. [CrossRef] 
14. Vos, R.J.; ten Brummelhuis, P.G.J.; Gerritsen, H. Integrated data-modelling approach for suspended sediment transport on a regional scale. Coast. Eng. 2000, 41, 177-200. [CrossRef]

15. Fettweis, M.; Nechad, B.; Van den Eynde, D. An estimate of the suspended particulate matter (SPM) transport in the southern North Sea using SeaWiFS images, in situ measurements and numerical model results. Cont. Shelf Res. 2007, 27, 1568-1583. [CrossRef]

16. Kunte, P.D.; Zhao, C.; Osawa, T.; Sugimori, Y. Sediment distribution study in the Gulf of Kachchh, India, from 3D hydrodynamic model simulation and satellite data. J. Mar. Syst. 2005, 55, 139-153. [CrossRef]

17. Park, E.; Latrubesse, E.M. Modeling suspended sediment distribution patterns of the Amazon River using MODIS data. Remote Sens. Environ. 2014, 147, 232-242. [CrossRef]

18. Sipelgas, L.; Raudsepp, U.; Kõuts, T. Operational monitoring of suspended matter distribution using MODIS images and numerical modelling. Adv. Space Res. 2006, 38, 2182-2188. [CrossRef]

19. Chauhan, O.S.; Menezes, A.A.A.; Jayakumar, S.; Malik, M.A.; Pradhan, Y.; Rajawat, A.S.; Nayak, S.R.; Bandekar, G.; Almeida, C.; Talaulikar, M.; et al. Influence of the macrotidal environment on the source to sink pathways of suspended flux in the Gulf of Kachchh, India: Evidence from the Ocean Colour Monitor (IRS-p4). Int. J. Remote Sens. 2007, 28, 3323-3339. [CrossRef]

20. Li, H.; Arias, M.; Blauw, A.; Los, H.; Mynett, A.E.; Peters, S. Enhancing generic ecological model for short-term prediction of Southern North Sea algal dynamics with remote sensing images. Ecol. Model. 2010, 221, 2435-2446. [CrossRef]

21. Stanev, E.; Kandilarov, R. Sediment dynamics in the Black Sea: Numerical modelling and remote sensing observations. Ocean Dyn. 2012, 62, 533-553. [CrossRef]

22. Luyten, P.J.; Jones, J.E.; Proctor, R.; Tabor, A.; Tett, P.; Wild-Allen, K. COHERENS-A Coupled Hydrodynamical-Ecological Model for Regional and Shelf Seas: User Documentation; MUMM Report; Management Unit of the Mathematical Models of the North Sea: Brussels, Belgium, 1999.

23. Liu, J.P.; Xu, K.H.; Li, A.C.; Milliman, J.D.; Velozzi, D.M.; Xiao, S.B.; Yang, Z.S. Flux and fate of Yangtze River sediment delivered to the East China Sea. Geomorphology 2007, 85, 208-224. [CrossRef]

24. Sternberg, R.W.; Larsen, L.H.; Miao, Y.T. Tidally driven sediment transport on the East China Sea continental shelf. Cont. Shelf Res. 1985, 4, 105-120. [CrossRef]

25. Lin, C.-M.; Zhuo, H.-C.; Gao, S. Sedimentary facies and evolution in the Qiantang River incised valley, eastern China. Mar. Geol. 2005, 219, 235-259. [CrossRef]

26. Milliman, J.D.; Meade, R.H. World-wide delivery of river sediment to the oceans. J. Geol. 1983, 91, 1-21. [CrossRef]

27. Ahn, J.-H.; Park, Y.-J.; Ryu, J.-H.; Lee, B.; Oh, I. Development of atmospheric correction algorithm for Geostationary Ocean Color Imager (GOCI). Ocean Sci. J. 2012, 47, 247-259. [CrossRef]

28. Choi, J.-K.; Park, Y.J.; Lee, B.R.; Eom, J.; Moon, J.-E.; Ryu, J.-H. Application of the Geostationary Ocean Color Imager (GOCI) to mapping the temporal dynamics of coastal water turbidity. Remote Sens. Environ. 2014, 146, 24-35. [CrossRef]

29. Choi, J.-K.; Park, Y.J.; Ahn, J.H.; Lim, H.-S.; Eom, J.; Ryu, J.-H. GOCI, the world's first geostationary ocean color observation satellite, for the monitoring of temporal variability in coastal water turbidity. J. Geophys. Res.: Oceans 2012, 117. [CrossRef]

30. Ryu, J.-H.; Han, H.-J.; Cho, S.; Park, Y.-J.; Ahn, Y.-H. Overview of geostationary ocean color imager (GOCI) and GOCI data processing system (GDPS). Ocean Sci. J. 2012, 47, 223-233. [CrossRef]

31. He, X.; Bai, Y.; Pan, D.; Tang, J.; Wang, D. Atmospheric correction of satellite ocean color imagery using the ultraviolet wavelength for highly turbid waters. Opt. Express 2012, 20, 20754-20770. [CrossRef] [PubMed]

32. He, X.; Bai, Y.; Pan, D.; Huang, N.; Dong, X.; Chen, J.; Chen, C.-T.A.; Cui, Q. Using geostationary satellite ocean color data to map the diurnal dynamics of suspended particulate matter in coastal waters. Remote Sens. Environ. 2013, 133, 225-239. [CrossRef]

33. Liang, B.-C.; Li, H.-J.; Lee, D.-Y. Bottom shear stress under wave-current interaction. J. Hydrodyn. Ser. B 2008, 20, 88-95. [CrossRef]

34. Marinov, D.; Norro, A.; Zaldívar, J.-M. Application of COHERENS model for hydrodynamic investigation of Sacca di Goro coastal lagoon (Italian Adriatic Sea shore). Ecol. Model. 2006, 193, 52-68. [CrossRef]

35. Shi, J.Z.; Li, C.; Dou, X.-P. Three-dimensional modeling of tidal circulation within the north and south passages of the partially-mixed Changjiang River Estuary, China. J. Hydrodyn. Ser. B 2010, 22, 656-661. [CrossRef] 
36. Guillou, N.; Chapalain, G. Modelling impact of northerly wind-generated waves on sediments resuspensions in the Dover Strait and adjacent waters. Cont. Shelf Res. 2011, 31, 1894-1903. [CrossRef]

37. Mellor, G.L.; Yamada, T. Development of a turbulence closure model for geophysical fluid problems. Rev. Geophys. 1982, 20, 851-875. [CrossRef]

38. Smagorinsky, J. General circulation experiments with the primitive equations. Mon. Weather Rev. 1963, 91, 99-164. [CrossRef]

39. Steinhorn, I. Salt flux and evaporation. J. phys. Oceanogr. 1991, 21, 1681-1683. [CrossRef]

40. Moon, I.-J. Impact of a coupled ocean wave-tide-circulation system on coastal modeling. Ocean Model. 2005, 8, 203-236. [CrossRef]

41. Jiang, W.; Pohlmann, T.; Sun, J.; Starke, A. SPM transport in the Bohai Sea: Field experiments and numerical modelling. J. Mar. Syst. 2004, 44, 175-188. [CrossRef]

42. Zhu, Y.; Chang, R. Preliminary study of the dynamic origin of the distribution pattern of bottom sediments on the continental shelves of the Bohai Sea, Yellow Sea and East China Sea. Estuar. Coast. Shelf Sci. 2000, 51, 663-680. [CrossRef]

43. DeMaster, D.J.; McKee, B.A.; Nittrouer, C.A.; Jiangchu, Q.; Guodong, C. Rates of sediment accumulation and particle reworking based on radiochemical measurements from continental shelf deposits in the East China Sea. Cont. Shelf. Res. 1985, 4, 143-158. [CrossRef]

44. Feng, Y.-J.; Li, Y.; Xie, Q.-C.; Zhang, L.-R. Morphology and activity of sedimentary interfaces of the Hangzhou Bay. Acta Oceanol. Sin. 1990, 12, 213-223.

45. Jiyu, C.; Cangzi, L.; Chongle, Z.; Walker, H.J. Geomorphological development and sedimentation in Qiantang Estuary and Hangzhou Bay. J. Coast. Res. 1990, 6, 559-572.

46. Xie, D.; Wang, Z.; Gao, S.; De Vriend, H.J. Modeling the tidal channel morphodynamics in a macro-tidal embayment, Hangzhou Bay, China. Cont. Shelf Res. 2009, 29, 1757-1767. [CrossRef]

47. Jones, S.; Jago, C.; Simpson, J. Modelling suspended sediment dynamics in tidally stirred and periodically stratified waters: Progress and pitfalls. Mix. Estuaries Coast. Seas 1996, 50, 302-324.

48. Lee, C.; Schwab, D.J.; Beletsky, D.; Stroud, J.; Lesht, B. Numerical modeling of mixed sediment resuspension, transport, and deposition during the March 1998 episodic events in southern Lake Michigan. J. Geophys. Res.: Oceans 2007, 112. [CrossRef]

49. Peckham, S.D. A new method for estimating suspended sediment concentrations and deposition rates from satellite imagery based on the physics of plumes. Comput. Geosci. 2008, 34, 1198-1222. [CrossRef]

50. Winterwerp, J.C. A simple model for turbulence induced flocculation of cohesive sediment. J. Hydraul. Res. 1998, 36, 309-326. [CrossRef]

(C) 2016 by the authors; licensee MDPI, Basel, Switzerland. This article is an open access article distributed under the terms and conditions of the Creative Commons by Attribution (CC-BY) license (http://creativecommons.org/licenses/by/4.0/). 